\title{
Erratum to: Primary MALT lymphoma of the urinary bladder in the background of interstitial cystitis
}

\author{
Ken Morita • Fumihiko Nakamura • Yasuhito Nannya • \\ Akira Nomiya - Shunya Arai • Motoshi Ichikawa • \\ Daichi Maeda • Yukio Homma • Mineo Kurokawa
}

Published online: 29 May 2012

(C) Springer-Verlag 2012

\section{Erratum to: Ann Hematol}

DOI 10.1007/s00277-012-1419-0

The original version of this article inadvertently contained a mistake. One co-author who has substantially contributed to this work was missing in the authors' list. The co-author is Dr. Daichi Maeda. All authors contributing to this work are now corrected and listed in the appropriate order.

The online version of the original article can be found at http://dx.doi.org/ 10.1007/s00277-012-1419-0.

K. Morita $\cdot$ F. Nakamura $\cdot$ Y. Nannya $\cdot$ S. Arai $\cdot$ M. Ichikawa $\cdot$

M. Kurokawa

Department of Hematology and Oncology,

Graduate School of Medicine, The University of Tokyo,

7-3-1 Hongo, Bunkyo-ku,

Tokyo 113-8655, Japan

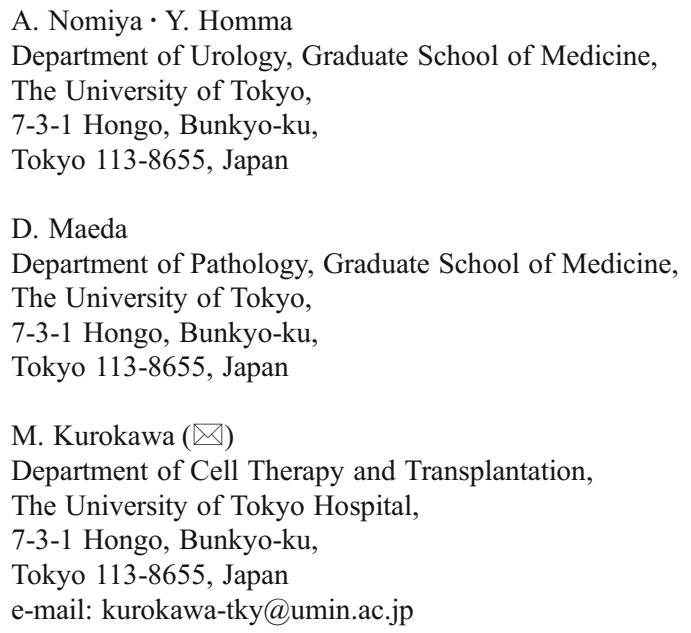

